\title{
A case of diphtheria in Sweden, October 2011
}

H Fredlund (hans.fredlund@orebroll.se) ${ }^{1}$, T Norén ${ }^{1}$, T Lepp $^{2}$, E Morfeldt ${ }^{2}$, B Henriques Normark ${ }^{2}$

1. Örebro University Hospital, Department of Laboratory Medicine, Clinical Microbiology, Örebro, Sweden

2. Swedish Institute for Communicable Disease Control (SMI), Solna, Sweden

Citation style for this article:

Fredlund H, Norén T, Lepp T, Morfeldt E, Henriques Normark B. A case of diphtheria in Sweden, October 2011.

Euro Surveill. 2011;16(50):pii=20038. Available online: http://www.eurosurveillance.org/ViewArticle.aspx?Articleld=20038

Article published on 15 December 2011

In October 2011, a child who had arrived in Sweden from Somalia presented with atypical tonsillitis, was treated with penicillin and the symptoms resolved. A throat swab was positive for toxigenic Corynebacterium diphtheriae. The child's family were then vaccinated with diphtheria, tetanus and pertussis vaccine and screened for $C$. diphtheriae. No secondary cases were found. A high level of adherence to childhood vaccination programmes is an effective way to protect populations against diphtheria.

\section{Case report}

In October 2011, a child who had recently migrated with their family from Somalia presented at a local general practitioner's (GP's) practice in Sweden with a sore throat and fever $\left(40^{\circ} \mathrm{C}\right)$. An atypical picture of unilateral tonsillitis led to the child being admitted to hospital, where penicillin was administered intravenously. The child was discharged the following day and was then treated at home with oral penicillin for one week, after which time the symptoms resolved. The other family members were healthy.

A throat swab taken on admission to hospital was cultured. The culture was positive for group A betahaemolytic streptococci. Due to the referral information of tonsillitis in a person who had recently arrived in the country and given the atypical clinical presentation, the local laboratory also cultured for Corynebacterium diphtheriae, which was positive. The isolate was fully sensitive to penicillin and erythromycin. Further analysis using PCR to detect the diphtheria toxin gene and the Elek test at the Swedish Institute for Communicable Disease Control (SMI, Solna) verified that the isolate was a toxin-producing strain of $C$. diphtheriae.

\section{Control measures}

Once the laboratory results had been obtained, the child's family (parent and seven children), were immediately vaccinated with diphtheria, tetanus and pertussis (DTP) vaccine and screened for $C$. diphtheriae. Only one sibling was found to carry $C$. diphtheriae and was treated with oral penicillin. This $C$. diphtheriae strain was later shown to be non-toxigenic.
The family had arrived in Sweden four weeks before the case's illness from a refugee camp in Africa. They had lived at one address since their arrival and had no other relatives in Sweden. There was no history of the case having attended daycare or school during the incubation period. As the family had had limited contact with others, contact tracing was not needed. The hospital staff had very limited contact (one overnight stay) with the patient who received immediate antibiotic treatment. Checking of vaccination history confirmed that all staff were fully vaccinated against diphtheria. All were healthy when the disease was diagnosed several days later, and to date still are. Follow-up of the family has been carried out by the local nurse, responsible for migrant health, and GP and to date, no secondary case has been detected.

\section{Background}

Diphtheria is caused by toxin-producing $C$. diphtheriae, C. ulcerans, and C. pseudotuberculosis. The best known and most widely studied species is $C$. diphtheriae, the most common causal agent of the disease.

The disease can result in an acute upper respiratory tract infection characterised by sore throat, fever (often $\left\langle 38{ }^{\circ} \mathrm{C}\right.$ ) and an adherent membrane on the tonsils, pharynx and/or nasal cavity. The severity of diphtheria is related to the degree of obstruction of the upper respiratory tract, caused by an acute bacterial toxic infection, and dissemination of the toxin which can cause myocarditis, polyneuritis and other systemic toxic effects. Overall, the case fatality rate may be as high as $20-30 \%$ in toxic forms [1]. A milder form of diphtheria may be restricted to cutaneous lesions even when caused by toxin-producing strains. The causative bacteria are spread by direct physical contact or breathing aerosolised secretions.

Due to the high degree of susceptibility of children to diphtheria, vaccination at an early age is universally advocated, for example, with DTP vaccine. Once quite common, diphtheria is rarely seen in developed nations due to the widespread use of DTP vaccine. Two minor outbreaks of diphtheria were notified in Sweden during the $1980 \mathrm{~s}[2,3]$ and only two cases of the disease 
due to $C$. diphtheriae have been diagnosed since 2001 (data not shown). Both cases were imported. The relative absence of diphtheria in Sweden is primarily due to the high vaccination coverage obtained through the childhood immunisation programme initiated in the 1950s. According to the programme, all children born in Sweden should receive four doses of diphtheria toxoid-containing vaccine. The first three doses should be administered within three months of age and the fourth dose should be given at the age of 10 years. All children of migrants are offered DTP immunisation as soon as they are in the Swedish health care system, often within weeks but at the latest within a few months after their arrival in Sweden. In 2010, a nationwide vaccination survey showed that $96 \%$ of all children aged 13 years living in Sweden were fully vaccinated with DTP vaccine and $2 \%$ were partly vaccinated (data not shown).

\section{Discussion}

Bacteriological analysis of a throat swab of the case reported here showed the presence of beta-haemolytic streptococci and toxigenic $C$. diphtheriae. Both pathogens may well have contributed to the clinical picture and the patient was successfully treated with penicillin.

In a country where the occurrence of diphtheria is low, such as Sweden, specific culturing for $C$. diphtheriae, C. ulcerans and C. pseudotuberculosis is rarely performed. Usually throat swabs are cultured without searching for these pathogens. As special media are required, a specific request for this culture has to be included on the referral note to the diagnostic laboratory, along with an indication of the unusual features of the disease and/or the origin of the patient. The local laboratory has to take that information into account for appropriate culturing. Otherwise diphtheria could be overlooked at an early stage of the disease or when presenting with atypical features and may cause secondary cases among susceptible people.

Diphtheria is a rarely diagnosed disease in western Europe and the small number are most commonly associated with travel to endemic countries. A few case reports from the United Kingdom and France have been published in recent years [4-6].

A high level of adherence to childhood vaccination programmes in every country is an effective way to protect populations against diphtheria. Adequate diagnostic tools and appropriate treatment of cases with atypical tonsillitis are also paramount to prevent further cases and potential outbreaks.
3. Christenson B, Hellström L, Aust-Kettis A. Diphtheria in Stockholm, with a theory concerning transmission. J Infect. 1989;19(2):177-83.

4. Perkins S, Cordery R, Nixon G, Abrahams A, Andrews J, White J, et al. Investigations and control measures following a non-travel-associated case of toxigenic Cornyebacterium diphtheriae, London, United Kingdom, December 2009-January 2010. Euro Surveill. 2010;15(16): pii=19544. Available from: http://www.eurosurveillance.org/ViewArticle. aspx?Articleld $=19544$

5. Taylor J, Saavedra-Campos M, Harwood D, Pritchard G, Raphaely N, Kapadia S, et al. Toxigenic Corynebacterium ulcerans infection in a veterinary student in London, United Kingdom, May 2010. Euro Surveill. 2010;15(31): pii=19634. Available from: http://www.eurosurveillance.org/ViewArticle. aspx?Articleld $=19634$

6. Rousseau C, Belchior E, Broche B, Badell E, Guiso N, Laharie I, et al. Diphtheria in the south of France, March 2011. Euro Surveill. 2011;16(19):pii=19867. Available from: http://www. eurosurveillance.org/ViewArticle.aspx?Articleld=19867
References

1. Eskola J, Lumio J, Vuopio-Varkila J. Resurgent diphtheria - are we safe? Br Med Bull. 1998;54(3):635-45.

2. Björkholm B, Olling S, Larsson P, Hagberg L. An outbreak of diphtheria among Swedish alcoholics. Infection. 1987;15(5):354-8. 